\title{
Emergent properties of electrically coupled smooth muscle cells
}

\author{
Michèle Koenigsberger*,1, Roger Sauser ${ }^{1}$, \\ Jean-Jacques Meister
}

Ecole Polytechnique Fédérale de Lausanne (EPFL), Laboratory of Cell Biophysics, CH-1015 Lausanne, Switzerland

Received 17 September 2004; accepted 2 February 2005

\begin{abstract}
Asynchronous and synchronous calcium oscillations occur in a variety of cells. A well-established pathway for intercellular communication is provided by gap junctions which connect adjacent cells and can mediate electrical and chemical coupling. Several experimental studies report that cells presenting only a transient increase when freshly dispersed may oscillate when they are coupled. Such observations suggest that the role of gap junctions is not only to coordinate calcium oscillations of adjacent cells. Gap junctions may also be important to generate oscillations. Here we illustrate the emergent properties of electrically coupled smooth muscle cells using a model that we recently proposed. A bifurcation analysis in the case of two cells reveals that synchronous and asynchronous calcium oscillations can be induced by electrical coupling. In a larger population of smooth muscle cells, electrical coupling may result in the creation of groups of cells presenting synchronous calcium oscillations. The elements of one group may be distant from each other. Moreover, our results highlight a general mechanism by which gap junctional electrical coupling can give rise to out of phase calcium oscillations in smooth muscle cells that are non-oscillating when uncoupled. All these observations remain true in the case of non-identical cells, except that the solution corresponding to synchronous calcium oscillations disappears and that the formation of groups is sensitive to the degree of heterogeneity.
\end{abstract}

(c) 2005 Society for Mathematical Biology. Published by Elsevier Ltd. All rights reserved.

\footnotetext{
* Corresponding author.

E-mail address: Michele.Koenigsberger@epfl.ch (M. Koenigsberger).

1 The first two authors contributed equally to this work.
} 


\section{Introduction}

Intracellular calcium oscillations are very common. Apart from smooth muscle cells (SMCs) (for a review, see Savineau and Marthan (2000)), they have been observed in neurons and in non-excitable cells like oocytes (Cuthbertson and Cobbold, 1985) and hepatocytes (Woods et al., 1986). Cytosolic calcium rises may be evoked by inositol 1,4,5trisphosphate $\left(\mathrm{IP}_{3}\right)$-linked agonist stimulation: after interacting with cell-surface receptors, agonists activate the phospholipase $\mathrm{C}$ (PLC) and induce the release of $\mathrm{IP}_{3} . \mathrm{IP}_{3}$ then releases calcium from intracellular stores (Minneman, 1988).

In populations of cells, a coordination of the calcium transients has been observed. Neighboring cells have been reported to present asynchronous or synchronous calcium oscillations (Tordjmann et al., 1997; Zang et al., 2001; Lamboley et al., 2003). In the case of arterial SMCs, synchronous calcium oscillations lead to vasomotion (Mauban et al., 2001; Sell et al., 2002; Lamboley et al., 2003), a cyclic variation of the arterial diameter. On the other hand, asynchronous calcium oscillations result in a tonic vessel contraction (Ruehlmann et al., 2000). Fanchaouy et al. (2005) have studied more or less dense preparations of freshly dispersed SMCs. Their results show that the probability of adenosine $5^{\prime}$-triphosphate triggered asynchronous calcium oscillations increases with the gap junctional coupling of SMCs. Moreover, Simpson and Ashley (1989) and Missiaen et al. (1994) have obtained spontaneous calcium oscillations in cultured aortic SMCs. The oscillations were present for cells in the confluent condition, but not in single cells or in cells in the subconfluent condition.

There have been several theoretical studies describing intercellular calcium waves (Sneyd et al., 1995; Höfer et al., 2001, 2002), and intercellular synchronization of calcium oscillations has been studied by coupling calcium oscillators by calcium (Höfer, 1999; Bindschadler and Sneyd, 2001). In a previous publication (Koenigsberger et al., 2004), we proposed a model describing a population of coupled SMCs. As SMCs are connected by non-selective gap junctions (Christ et al., 1992), we assumed a gap junctional communication by means of electrical coupling, $\mathrm{IP}_{3}$ diffusion, and calcium diffusion. Our model reproduces well experimental observations like asynchronous calcium flashings, recruitment of responding stimulated cells and vasomotion in absence of endothelium (Hamada et al., 1997; Peng et al., 2001; Sell et al., 2002; Haddock et al., 2002; Lamboley et al., 2003). With our particular set of parameter values, a weak calcium coupling is required to obtain a synchronization of calcium oscillations. In contrast with $\mathrm{IP}_{3}$ diffusion which did not play a significant role, electrical coupling revealed a number of interesting facts.

In the present article, we examine in more detail the properties of electrically coupled calcium oscillators under agonist stimulation. We provide a detailed bifurcation analysis of two electrically coupled SMCs. We show that isolated cells which are not oscillating at a certain agonist concentration may begin to oscillate when they are electrically coupled. The mechanism underlying this phenomenon of generation of oscillations is exposed. Moreover we observe that electrical coupling can give rise to out of phase calcium oscillations. We then extend our discussion to three electrically coupled cells and to larger populations of cells. Finally, we consider non-identical cells to see how the introduction of heterogeneity affects our conclusions. 


\section{Mathematical model}

\subsection{Single cell model}

We adopt the approach of Koenigsberger et al. (2004) to describe the calcium dynamics of a single SMC $i$. Our model has five variables: the calcium concentration in the cytosol $c_{i}$, the calcium concentration in the sarcoplasmic reticulum (SR) $s_{i}$, the cell membrane potential $v_{i}$, the open state probability of calcium activated potassium channels $w_{i}$, and the $\mathrm{IP}_{3}$ concentration $I_{i}$. These variables enter a set of nonlinear differential equations that can be conveniently written as follows:

$$
\begin{aligned}
\frac{\mathrm{d} c_{i}}{\mathrm{~d} t} & =J_{\mathrm{IP}_{i}}-J_{\mathrm{VOCC}_{i}}+J_{\mathrm{Na} / \mathrm{Ca}_{i}}-J_{\mathrm{SRuptak}_{i}}+J_{\mathrm{CICR}_{i}}-J_{\mathrm{extrusion}_{i}}+J_{\text {leak }_{i}}, \\
\frac{\mathrm{d} s_{i}}{\mathrm{~d} t} & =J_{\mathrm{SRuptake}_{i}}-J_{\mathrm{CICR}_{i}}-J_{\mathrm{leak}_{i}}, \\
\frac{\mathrm{d} v_{i}}{\mathrm{~d} t} & =\gamma\left(-J_{\mathrm{Na} / \mathrm{K}_{i}}-J_{\mathrm{Cl}_{i}}-2 J_{\mathrm{VOCC}_{i}}-J_{\mathrm{Na} / \mathrm{Ca}_{i}}-J_{\mathrm{K}_{i}}\right), \\
\frac{\mathrm{d} w_{i}}{\mathrm{~d} t} & =\lambda\left(K_{\text {activation }_{i}}-w_{i}\right), \\
\frac{\mathrm{d} I_{i}}{\mathrm{~d} t} & =J_{\mathrm{PLC}_{\mathrm{agonist}_{i}}+J_{\mathrm{PLC} \delta_{i}}-J_{\text {degrad }_{i} .}}
\end{aligned}
$$

The various terms appearing on the right-hand side of these equations are detailed in Parthimos et al. (1999) and Höfer et al. (2002), and we briefly review them in Appendix A. A rise in agonist concentration is simulated by an increase of the PLC rate $J_{\mathrm{PLC}_{\text {agonist }}}$.

\subsection{Electrical intercellular communication}

We consider a two-dimensional model in which SMCs communicate electrically via gap junctions. As gap junctions connect adjacent cells, a cell is assumed to communicate only with its first neighbors. Gap junctions between two neighboring cells are modeled by a single global conductance or permeability, which is supposed to be the same in every direction. Moreover, the intercellular couplings are assumed to be bidirectional and symmetric as we study homocellular communications.

To model the electrical coupling between cells, a term

$$
V_{\text {coupling }_{i}}=-g \sum_{j}\left(v_{i}-v_{j}\right)
$$

is added to Eq. (3) for each cell $i$. The gap junctional electrical coupling coefficient $g$ is related to the gap junctional conductance $G$ by $g=G / C_{\mathrm{m}}$, where $C_{\mathrm{m}}$ is the cell membrane capacitance. The conductance $G$ reflects the composite junctional permeability to small cytoplasmic ions (Verselis et al., 1986) between the cell $i$ and its first neighbors $j$. In the present study, $g$ is treated as a free parameter. 

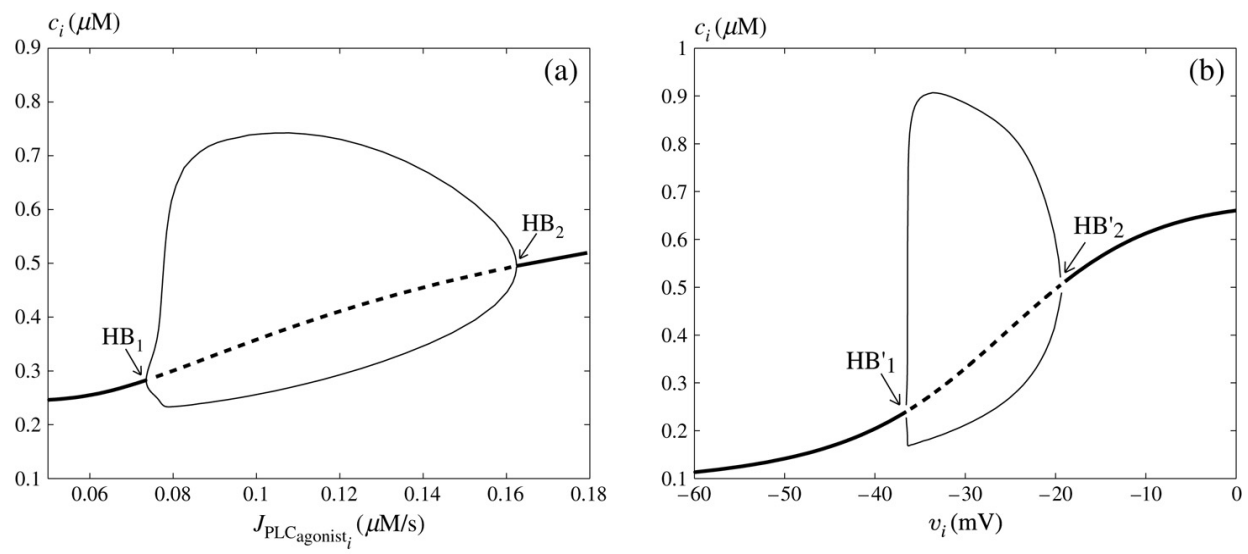

Fig. 1. Bifurcation diagrams of an isolated SMC stimulated by an agonist (thick solid line: stable rest state, thick dashed line: unstable rest state, thin solid line: minima and maxima of stable oscillations). We have represented the cytosolic calcium concentration $c_{i}$ with respect to (a) the rate of PLC $J_{\mathrm{PLC}_{\text {agonist }}}$ and (b) the membrane potential $v_{i}\left(v_{i}\right.$ is treated here as a parameter and $J_{\mathrm{PLC}_{\text {agonist }}}$ is set to $\left.0.05 \mu \mathrm{M} / \mathrm{s}\right)$. $\mathrm{HB}_{1}, \mathrm{HB}_{2}, \mathrm{HB}_{1}^{\prime}$ and $\mathrm{HB}_{2}^{\prime}$ denote Hopf bifurcations.

\subsection{Numerical methods}

Using a fourth order Runge-Kutta method implemented in $\mathrm{C}$ (with a time step in the range [0.003-0.00003] s), the model equations were integrated on a two-dimensional grid of cells. For intercellular communication, we have considered three possibilities: (i) A cell is connected to its first neighbors in the "horizontal" and "vertical" directions. It then communicates with four cells, or less if it is situated near the border. (ii) A cell is connected to its first neighbors in the "horizontal", "vertical" and "diagonal" directions. It then communicates with eight cells, or less if it is situated near the border. (iii) A cell is connected to its first neighbors in the "horizontal" and "vertical" directions, and periodic conditions are imposed on the boundary. Every cell then communicates with four cells. Within each cell, the calcium and membrane potential dynamics are described by Eqs. (1)-(5) complemented with term (6). We also used the software XPP and AUTO, as implemented in XPPAUT by B. Ermentrout (http://www.pitt.edu/ phase/) to complete our analysis: the equations in the case of one and two coupled cells were solved with XPP, and AUTO was used for bifurcation diagrams. All stable parts of branches indicated by AUTO have been found in our numerical simulations.

\section{Results}

\subsection{Single cell}

\subsubsection{Bifurcation analysis}

The behavior of the cytosolic calcium concentration $c_{i}$ of an isolated SMC with respect to the agonist activated PLC-rate, $J_{\mathrm{PLC}_{\text {agonist }}}$, is shown in Fig. 1(a). At low values of $J_{\mathrm{PLC}_{\text {agonist }}}$ (i.e. at low agonist concentration), the cytosolic calcium level is in a stable 

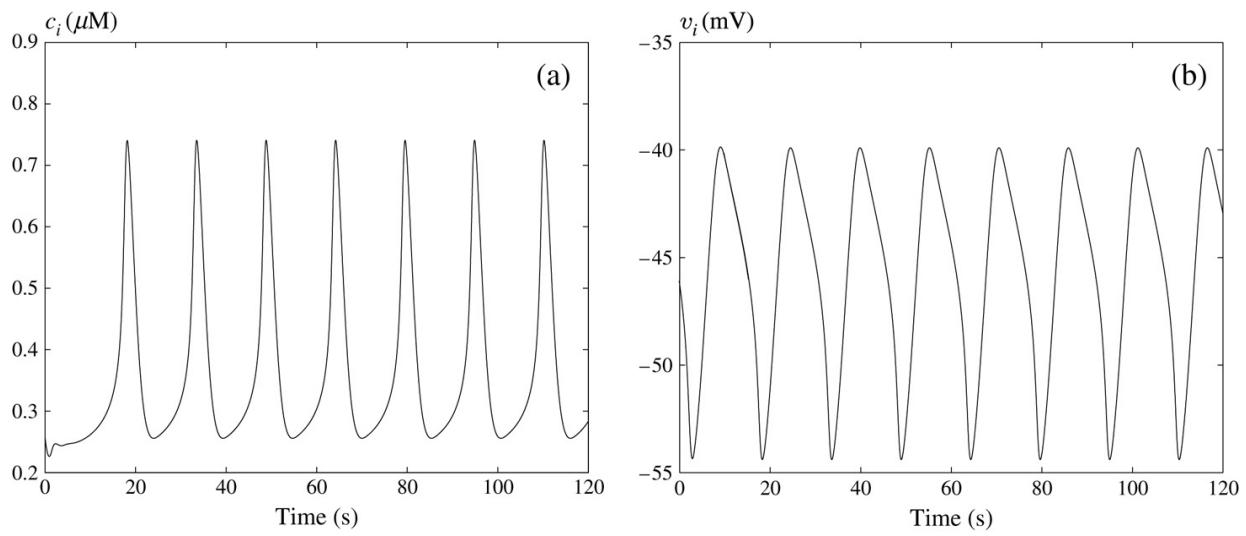

Fig. 2. Numerical simulation for (a) the cytosolic calcium concentration $c_{i}$ and (b) membrane potential $v_{i}$ of one isolated cell at $J_{\mathrm{PLC}_{\text {agonist }}}=0.1 \mu \mathrm{M} / \mathrm{s}$.

steady state. Increasing the agonist concentration, a Hopf bifurcation, $\mathrm{HB}_{1}$, occurs: the steady state becomes unstable and the calcium level begins to oscillate. There is a single branch of periodic orbits. A numerical simulation showing calcium and membrane potential oscillations is given in Fig. 2. The membrane potential oscillates at the same frequency as calcium. Numerical simulations show that the mean calcium level and the frequency of the oscillations become higher with increasing values of $J_{\mathrm{PLC}_{\text {agonist }}}$. Finally, the diagram of Fig. 1(a) has another Hopf bifurcation, $\mathrm{HB}_{2}$, from which the steady state becomes stable again; the cytosolic calcium level is high and does not oscillate anymore.

\subsubsection{Intracellular oscillator}

The equations for cytosolic calcium concentration $\left(c_{i}\right)$ and calcium concentration in the SR $\left(s_{i}\right)$ constitute the intracellular oscillator. With the parameter values chosen (see Table A.1 in Appendix A), they are responsible for the oscillations. This is in agreement with the experimental findings of Hamada et al. (1997), Lee et al. (2001) and Haddock et al. (2002). The membrane potential $v_{i}$ and the open state probability of potassium channels $w_{i}$ follow only passively the calcium oscillations. This can be seen in Fig. 1(b) which represents the cytosolic calcium concentration $c_{i}$ with respect to the membrane potential $v_{i}$. In contrast with the rest of our study, $v_{i}$ is treated as a parameter in this bifurcation diagram. At low values of the membrane potential, the calcium level is in a stable steady state. Raising $v_{i}$ increases the calcium level by triggering the influx of calcium through voltage operated calcium channels, and a Hopf bifurcation, $\mathrm{HB}_{1}^{\prime}$, occurs. The steady state becomes unstable and the calcium level begins to oscillate. Finally, a second Hopf bifurcation, $\mathrm{HB}_{2}^{\prime}$, leads to a stable steady state with a high sustained cytosolic calcium level that does not oscillate anymore.

\subsection{Electrically coupled cells}

\subsubsection{Bifurcation analysis for two coupled cells}

Three bifurcation diagrams for the cytosolic calcium concentration $c_{i}$ in the case of two electrically coupled cells are given in Fig. 3. In these diagrams, the coupling parameter 

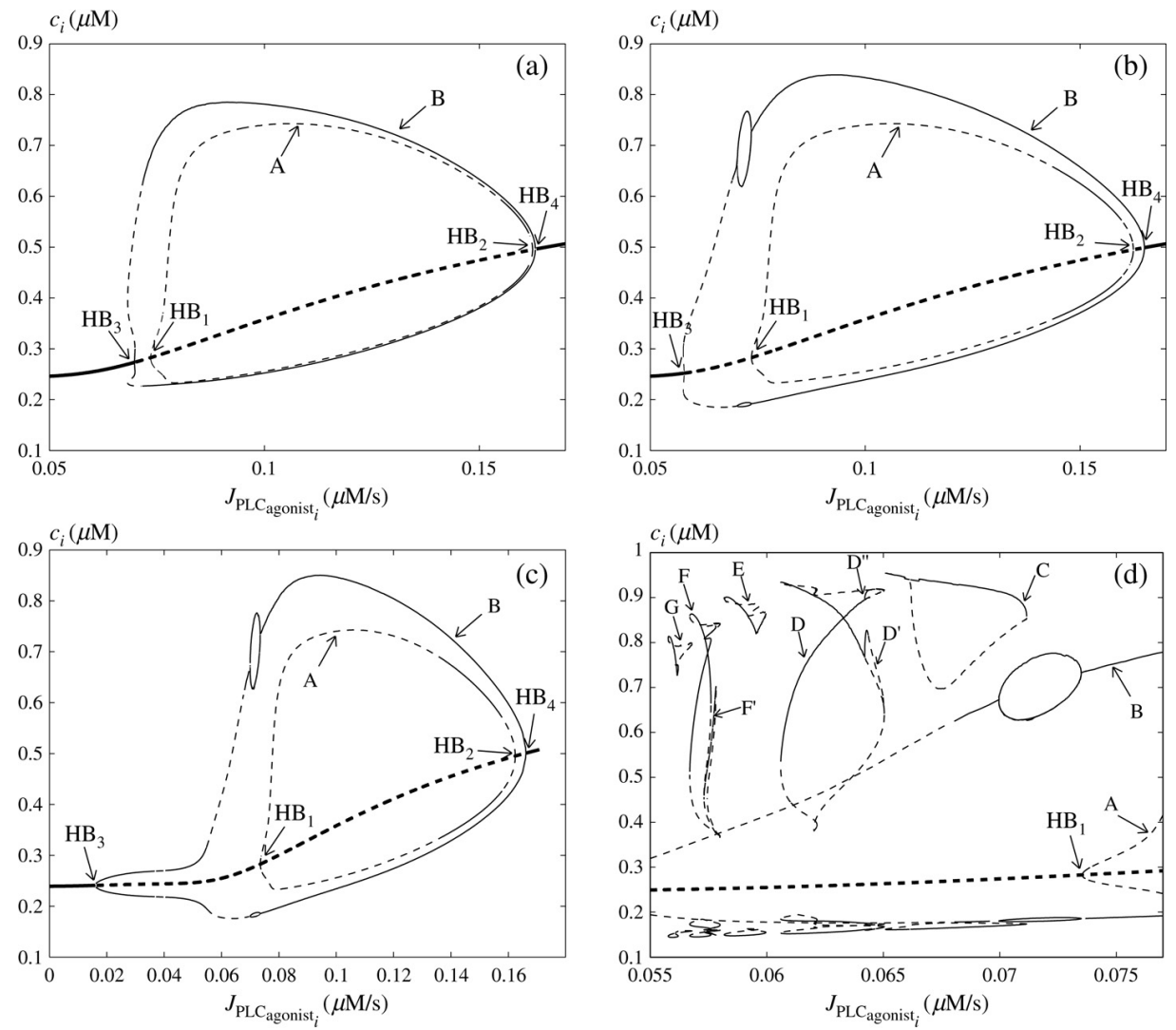

Fig. 3. Bifurcation diagrams for the cytosolic calcium concentration $c_{i}$ of two identical electrically coupled cells (a) $g=1 \mathrm{~s}^{-1}$. (b) $g=10 \mathrm{~s}^{-1}$. (c) $g=100 \mathrm{~s}^{-1}$. (d) Details not represented in panel (c) (thick solid line: stable rest state, thick dashed line: unstable rest state, thin solid line: minima and maxima of stable oscillations, thin dashed line: minima and maxima of unstable oscillations). $\operatorname{HB}_{h}(h=1, \ldots, 4)$ denotes a Hopf bifurcation. Single capital letters label branches of periodic orbits.

$g$ is set to (a) $1 \mathrm{~s}^{-1}$, (b) $10 \mathrm{~s}^{-1}$ and (c) $100 \mathrm{~s}^{-1}$. There are four Hopf bifurcations $\mathrm{HB}_{h}(h=1, \ldots, 4)$, and two branches, denoted A and B, are emanating from them. For two uncoupled cells $\left(g=0 \mathrm{~s}^{-1}\right)$, branch B coincides with branch A (as in Fig. 1(a)). At $g \neq 0 \mathrm{~s}^{-1}$, the branches are distinct. Increasing $g$ moves branch B away from branch A. It shifts $\mathrm{HB}_{3}$ to the left, $\mathrm{HB}_{4}$ to the right and the small stable domain on branch $\mathrm{A}$ away from $\mathrm{HB}_{2}$. In panels (a)-(c) of Fig. 3, there is a region between $\mathrm{HB}_{3}$ and $\mathrm{HB}_{1}$ where no attractor is visible. The periodic branches $\mathrm{C}-\mathrm{G}$ existing in this region are detailed in panel (d) of Fig. 3 in the case $g=100 \mathrm{~s}^{-1}$.

It is worth noting that for large values of $g$, the bifurcation diagram is not identical to that of a single cell. Indeed the equation for membrane potential is not responsible for oscillations and strong electrical coupling disrupts the intracellular oscillator. The bifurcation diagram would correspond to that of an uncoupled cell if cells were strongly 
coupled by calcium diffusion (Bindschadler and Sneyd, 2001; Koenigsberger et al., 2004), as the equations for calcium concentrations make up the oscillator. Strong calcium coupling forces the calcium concentration to be the same for both cells and this calcium concentration is the solution of the equations for an uncoupled cell.

Synchronous calcium oscillations (branch A). The two Hopf bifurcations $\mathrm{HB}_{1}$ and $\mathrm{HB}_{2}$ of the single cell bifurcation diagram (see Fig. 1(a)) are still present at the same positions. The branch of periodic orbits emanating from them corresponds to synchronous calcium oscillations, during which membrane potential and calcium concentration oscillate in phase at the same frequency. This is necessarily the case, as cells with identical initial conditions must present the same oscillatory solution as an uncoupled cell. However with respect to the single cell bifurcation diagram, the branch has become unstable, except for a small domain.

Antiphase calcium oscillations (branch B). The presence of the two Hopf bifurcations $\mathrm{HB}_{3}$ and $\mathrm{HB}_{4}$ results from the coupling of the two cells. The bifurcations $\mathrm{HB}_{3}$ and $\mathrm{HB}_{4}$ give rise to a branch of periodic orbits corresponding to antiphase calcium oscillations associated to synchronous membrane potentials: calcium oscillations are out of phase, but each calcium oscillation induces a membrane potential oscillation in the other cell. Thus membrane potential oscillates twice while calcium only once. This branch is stable for most agonist concentrations.

Although electrical coupling tends to synchronize membrane potential oscillations, they are never completely synchronous. Indeed, as membrane potential follows the calcium concentration in each cell and electrical coupling tends to produce out of phase calcium oscillations, the coupling term is always non-zero. In our study the term "synchronous" is used even when the oscillations only tend to be synchronous and the coupling term is never zero.

Examples of numerical simulations of two electrically coupled cells $\left(g=100 \mathrm{~s}^{-1}\right)$ are given in Fig. 4. Fig. 4(a) shows two cells starting from an initial condition where they are

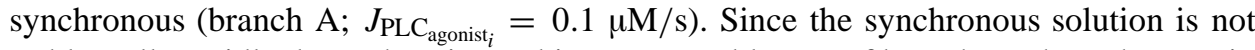
stable, cells rapidly desynchronize and jump to a stable part of branch B where they are in antiphase.

Oscillations between $\mathbf{H B}_{3}$ and $\mathbf{H B}_{1}$ (branches $\mathbf{C}-\mathbf{G}$ ). Between the Hopf bifurcations $\mathrm{HB}_{3}$ and $\mathrm{HB}_{1}$, we have found five branches of periodic orbits containing many perioddoubling bifurcations. On branches $\mathrm{D}$ and $\mathrm{F}$, we have represented the branches $\mathrm{D}^{\prime}, \mathrm{D}^{\prime \prime}$ and $\mathrm{F}^{\prime}$ emanating from period-doubling bifurcations. These sub-branches present further period-doubling bifurcations. The numerical solutions between the traced branches are complex, so there seem to be cascades of period-doubling bifurcations leading to complex behaviors. A numerical simulation corresponding to branch $\mathrm{C}$ is given in Fig. 4(b) for

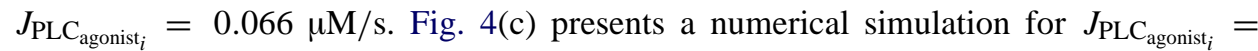
$0.061 \mu \mathrm{M} / \mathrm{s}$ corresponding to branch D. Note that in this case the two cells oscillate with different amplitudes. In Fig. 4(b) and (c), the orbits wind three, respectively two, times around the steady state before repeating. Finally, Fig. 4(d) is more complex and shows no periodicity. It corresponds to an agonist concentration of $J_{\mathrm{PLC}_{\text {agonist }}}=0.055 \mu \mathrm{M} / \mathrm{s}$, i.e. to a region where we have not found any branch of periodic orbits. 

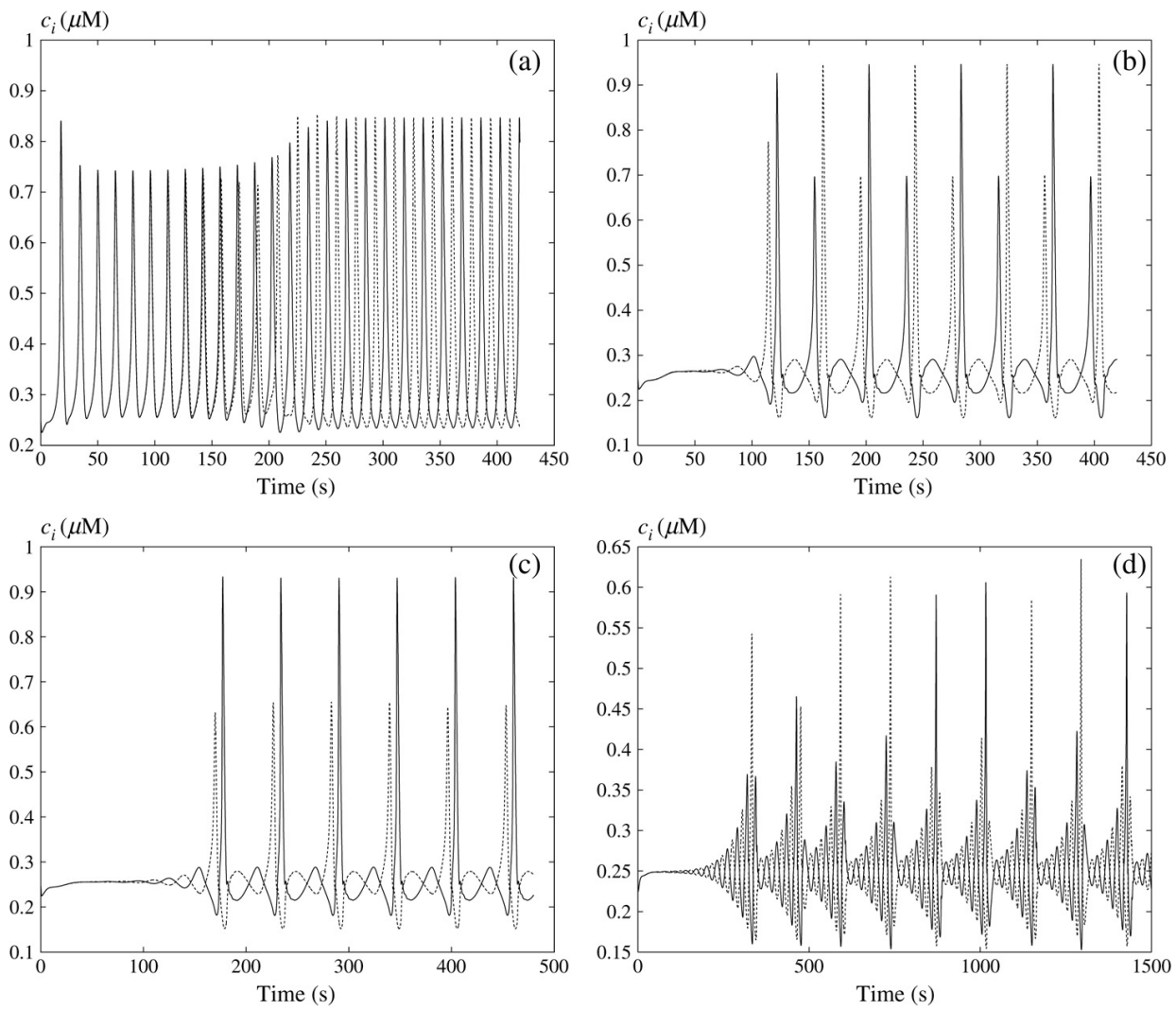

Fig. 4. Numerical simulations of the cytosolic calcium concentrations $c_{i}$ of two identical electrically coupled

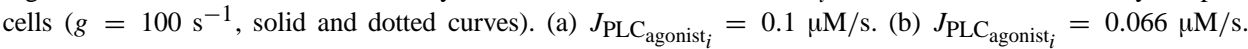
(c) $J_{\mathrm{PLC}_{\text {agonist }}}=0.061 \mu \mathrm{M} / \mathrm{s}$. (d) $J_{\mathrm{PLC}_{\text {agonist }}}=0.055 \mu \mathrm{M} / \mathrm{s}$.

\subsubsection{Generation of oscillations in the two-cell case}

As the additional Hopf bifurcations $\mathrm{HB}_{3}$ and $\mathrm{HB}_{4}$ of the asynchronous branch $\mathrm{B}$ are occurring before $\mathrm{HB}_{1}$ and after $\mathrm{HB}_{2}$ (see Fig. 3), isolated cells which are not oscillating at a certain agonist concentration may begin to oscillate when they are coupled. In other words, electrical coupling generates out of phase calcium oscillations in SMCs.

The generation of oscillations can be explained in the following way: suppose that the calcium concentration of one cell is moved away from its steady state and presents a calcium spike. Due to the electrical coupling, the second cell tends to prevent the membrane potential of the first cell from following its calcium increase. During the calcium spike, this results in different values of membrane potential for an electrically coupled cell than for an isolated cell. These changes in membrane potential values alter the calcium dynamics and may bring about oscillations. This can be intuitively understood from Fig. 1(b): starting from membrane potential values for which the calcium concentration is not oscillating, changes of the membrane potential may modify the system in such a way that it encounters 
(a)

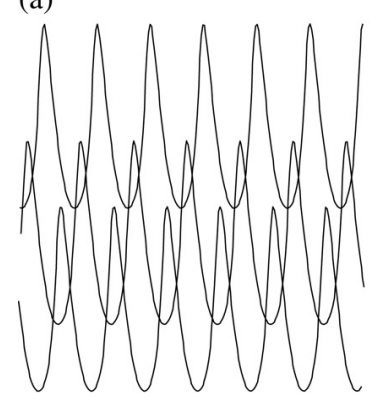

(b)

(c)
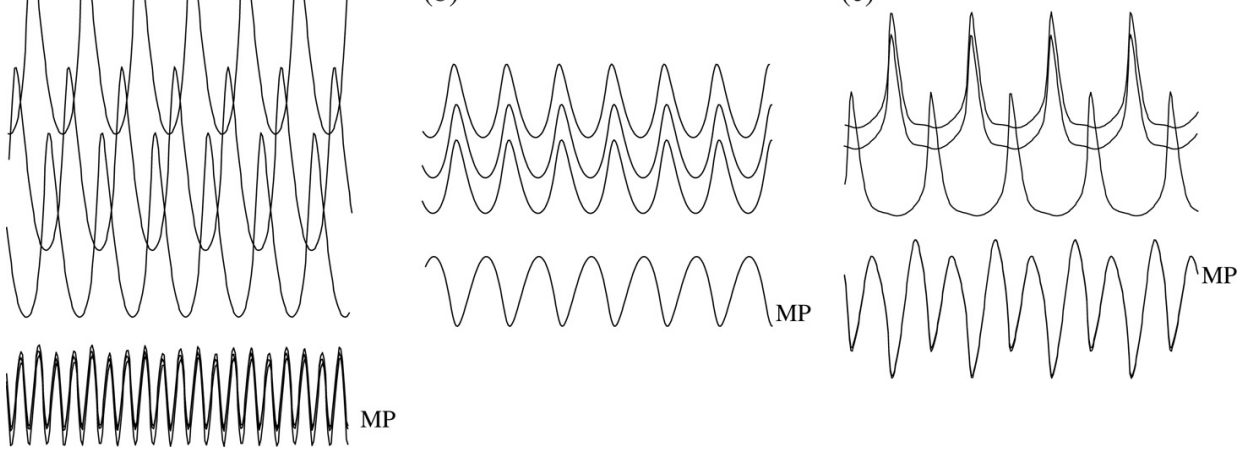

Fig. 5. Numerical simulations of three identical mutually electrically coupled cells $\left(g=100 \mathrm{~s}^{-1}\right)$. In each panel, the bottom curve represents the in phase membrane potential (MP) oscillations and the other curves give the

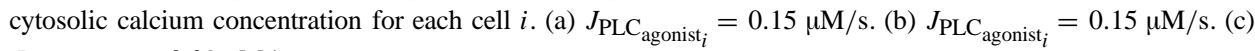
$J_{\mathrm{PLC}_{\text {agonist }}}=0.09 \mu \mathrm{M} / \mathrm{s}$.

a Hopf bifurcation. At low agonist concentration (in the region between $\mathrm{HB}_{3}$ and $\mathrm{HB}_{1}$ in Fig. 3) oscillations are generated because electrical coupling results in higher values of the membrane potential. In the region between $\mathrm{HB}_{2}$ and $\mathrm{HB}_{4}$, electrical coupling decreases the values of the membrane potential, which also brings about oscillations.

Physiologically, in the region between $\mathrm{HB}_{3}$ and $\mathrm{HB}_{1}$, electrical coupling may entail for example that the amplitude of the calcium induced membrane potential hyperpolarization is smaller than for an isolated cell. The calcium influx through voltage operated calcium channels (term $J_{\mathrm{VOCC}_{i}}$ in Eqs. (1) and (3)) is then less decreased during hyperpolarization, and thus the cytosolic calcium level may become higher and begin to oscillate.

Fig. 4(b)-(d) illustrate this phenomenon of generation of oscillations. Cells start from an initial condition between $\mathrm{HB}_{3}$ and $\mathrm{HB}_{1}$. The steady state has become unstable in this region, which brings about oscillations.

\subsubsection{Three coupled cells}

The generation of oscillations is also present in the case of three cells which are electrically coupled. Electrical coupling essentially gives rise to one third of a period out of phase calcium oscillations and in phase membrane potential oscillations. An example of numerical simulation for $J_{\mathrm{PLC}_{\text {agonist }}}=0.15 \mu \mathrm{M} / \mathrm{s}$ is shown in Fig. 5(a). As for the two-cell case, this solution can be found on a wide range of agonist concentration. Note that the membrane potentials are not perfectly synchronous. They are more synchronous at lower agonist concentration, i.e. at lower frequencies. We also obtain a solution with in phase calcium oscillations, but only for a limited range of agonist concentration (see Fig. 5(b) for $J_{\mathrm{PLC}_{\text {agonist }}}=0.15 \mu \mathrm{M} / \mathrm{s}$ ). Moreover, we observe a solution with two in phase and one in antiphase calcium concentrations (see Fig. 5(c) for $J_{\mathrm{PLC}_{\text {agonist }}}=0.09 \mu \mathrm{M} / \mathrm{s}$ ). In this case, membrane potential oscillations present two peaks corresponding to the calcium oscillations of two cells in phase and one cell in antiphase respectively. 


\subsubsection{Population of cells}

If one increases the number of coupled SMCs, we still observe the generation of oscillations, and simultaneous out of phase calcium oscillations and in phase membrane potential oscillations of neighboring cells. As for the two-cell case, electrically coupled neighboring cells tend to have out of phase calcium oscillations. However we observe that for larger numbers of cells, not all cells are out of phase: there are always groups of cells consisting of neighboring and distant cells that present in phase calcium oscillations. This phenomenon is due to the fact that in each cell the membrane potential follows passively the calcium oscillations (Fig. 2), while electrical coupling among cells tends to synchronize the membrane potentials and to desynchronize the calcium concentrations. Therefore cells organize themselves by becoming synchronous in groups to less perturb membrane potential dynamics with respect to calcium dynamics in each single cell. So there are two opposite effects, one tending to create out of phase calcium oscillations and the other tending to let membrane potential be in phase with calcium oscillations in each cell. The result of these two effects is an interesting pattern of synchronous and asynchronous oscillations in a population of electrically coupled cells. Implementing the three different possibilities for intercellular communication (see above in the section "Numerical methods"), we observe similar behaviors.

Examples of numerical simulations for 4, 6 and 25 cells coupled to their first neighbors $\left(g=100 \mathrm{~s}^{-1}\right)$ are given in Fig. $6\left(\mathrm{PLC}_{\text {agonist }_{i}}=0.07 \mu \mathrm{M} / \mathrm{s}\right)$. In this figure, in phase oscillating cells are depicted by the same gray shade. Starting from the unstable steady state, oscillations emerge and cells organize themselves in a regular way. In Fig. 6(a), the generated calcium oscillations are out of phase for the four cells. For each cell the membrane potential oscillates then four times during one calcium oscillation. Considering the three different possibilities for intercellular communication, we have not observed a solution for which all cells oscillate out of phase for a population larger than four cells. For instance, in Fig. 6(b), not all oscillations of neighboring cells are out of phase. This is due to the fact that membrane potential tends to oscillate in phase with the calcium concentration in each of the six cells. Fig. 6(c) shows a simulation of 25 cells. There are three groups of in phase calcium oscillating cells, and cells in each group can be adjacent as well as being situated far away from each other. For each cell membrane potential oscillates then three times during one calcium oscillation. Thus with this mechanism synchronous oscillations can appear for cells disposed at a long distance from each other, and out of phase oscillations can occur for adjacent cells.

For each population of cells different stable configurations exist. Therefore our simulations show only examples of them. For instance, in the four cell case we have also found a stable pattern with two in phase calcium oscillating cells. Fig. 7 shows two possible configurations in the case of 100 cells. By further increasing the number of cells to a few hundred, we still observe the formation of three or four groups of cells oscillating in phase. The time required to reach a stable configuration increases with the number of cells.

\subsubsection{Non-identical cells}

In nature, perfectly identical cells do not exist. Individual SMCs may have slightly different intrinsic frequencies, and it is therefore important to investigate how the 
(a)

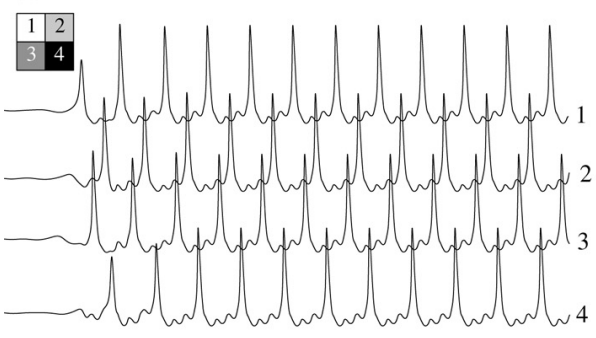

(b)

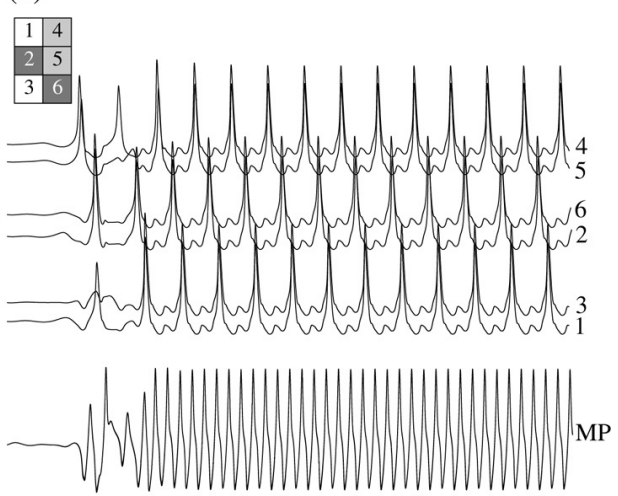

(c)

\begin{tabular}{|l|l|l|l|l|}
\hline 1 & 6 & 11 & 16 & 21 \\
\hline 2 & 7 & 12 & 17 & 22 \\
\hline 3 & 8 & 13 & 18 & 23 \\
\hline 4 & 9 & 14 & 19 & 24 \\
\hline 5 & 10 & 15 & 20 & 25 \\
\hline
\end{tabular}

Fig. 6. Numerical simulations of several identical cells electrically coupled to their first neighbors in the "horizontal" and "vertical" directions $\left(g=100 \mathrm{~s}^{-1}, J_{\mathrm{PLC}_{\text {agonist }}}=0.07 \mu \mathrm{M} / \mathrm{s}\right)$. The grid shows the arrangement of the cells denoted by numbers. The calcium oscillations of cells colored with the same gray shade are in phase. In panels (a) and (b), the bottom curve represents the in phase membrane potential (MP) oscillations and the other curves give the cytosolic calcium concentration for each cell $i$. (a) 4 cells. (b) 6 cells. (c) 25 cells.

introduction of heterogeneity among cells affects the above described behaviors. To model non-identical cells, we choose to vary the amplitude $F$ of the quantity $J_{\mathrm{IP} 3_{i}}$ (term (A.1) in Appendix A) which represents the calcium release from the stores possessing $\mathrm{IP}_{3}$ receptors. In other words, we consider cells with different densities of $\mathrm{IP}_{3}$ receptors, which is a reasonable assumption (Tasker et al., 1999; Haberichter et al., 2002). For the first cell, SMC 1, we keep $F_{1}=0.23 \mu \mathrm{M} / \mathrm{s}$, and for the second cell, SMC $2, F_{2}$ is varied in the range [0.229-0.25] $\mu \mathrm{M} / \mathrm{s}$. According to the experiments of Hamada et al. (1997), the oscillation frequencies of stimulated SMCs are narrowly distributed around a mean value. Therefore, we do not consider values of $F_{2}$ higher than $0.25 \mu \mathrm{M} / \mathrm{s}$, as the corresponding intrinsic frequencies would be too different between SMC 1 and SMC 2.

Bifurcation diagrams for two electrically coupled cells $\left(g=100 \mathrm{~s}^{-1}\right)$ with $F_{1}=$ $0.23 \mu \mathrm{M} / \mathrm{s}$ and $F_{2}=0.234 \mu \mathrm{M} / \mathrm{s}$ are given in Fig. 8, (a) and (b). This corresponds to two cells with intrinsic frequencies $f_{1}=0.065 \mathrm{~Hz}$ and $f_{2}=0.067 \mathrm{~Hz}$ at $J_{\mathrm{PLC}_{\text {agonist }}}=$ $0.1 \mu \mathrm{M} / \mathrm{s}$. As in the case of two identical SMCs (see Fig. 3(c)), there are four Hopf bifurcations. The Hopf bifurcations $\mathrm{HB}_{1}$ and $\mathrm{HB}_{2}$ give rise to a branch of periodic orbits corresponding to in phase calcium oscillations and membrane potential oscillations (branch A). With respect to the diagram of identical cells, the stable part of this branch has 
(a)

\begin{tabular}{|l|l|l|l|l|l|l|l|l|l|}
\hline 1 & 11 & 21 & 31 & 41 & 51 & 61 & 71 & 81 & 91 \\
\hline 2 & 12 & 22 & 32 & 42 & 52 & 62 & 72 & 82 & 92 \\
\hline 3 & 13 & 23 & 33 & 43 & 53 & 63 & 73 & 83 & 93 \\
\hline 4 & 14 & 24 & 34 & 44 & 54 & 64 & 74 & 84 & 94 \\
\hline 5 & 15 & 25 & 35 & 45 & 55 & 65 & 75 & 85 & 95 \\
\hline 6 & 16 & 26 & 36 & 46 & 56 & 66 & 76 & 86 & 96 \\
\hline 7 & 17 & 27 & 37 & 47 & 57 & 67 & 77 & 87 & 97 \\
\hline 8 & 18 & 28 & 38 & 48 & 58 & 68 & 78 & 88 & 98 \\
\hline 9 & 19 & 29 & 39 & 49 & 59 & 69 & 79 & 89 & 99 \\
\hline 10 & 20 & 30 & 40 & 50 & 60 & 70 & 80 & 90 & 100 \\
\hline
\end{tabular}

(b)

\begin{tabular}{|l|l|l|l|l|l|l|l|l|l|}
\hline 1 & 11 & 21 & 31 & 41 & 51 & 61 & 71 & 81 & 91 \\
\hline 2 & 12 & 22 & 32 & 42 & 52 & 62 & 72 & 82 & 92 \\
\hline 3 & 13 & 23 & 33 & 43 & 53 & 63 & 73 & 83 & 93 \\
\hline 4 & 14 & 24 & 34 & 44 & 54 & 64 & 74 & 84 & 94 \\
\hline 5 & 15 & 25 & 35 & 45 & 55 & 65 & 75 & 85 & 95 \\
\hline 6 & 16 & 26 & 36 & 46 & 56 & 66 & 76 & 86 & 96 \\
\hline 7 & 17 & 27 & 37 & 47 & 57 & 67 & 77 & 87 & 97 \\
\hline 8 & 18 & 28 & 38 & 48 & 58 & 68 & 78 & 88 & 98 \\
\hline 9 & 19 & 29 & 39 & 49 & 59 & 69 & 79 & 89 & 99 \\
\hline 10 & 20 & 30 & 40 & 50 & 60 & 70 & 80 & 90 & 100 \\
\hline
\end{tabular}

Fig. 7. Numerical simulations of a population of 100 identical cells electrically coupled to their first neighbors in the "horizontal" and "vertical" directions $\left(g=100 \mathrm{~s}^{-1}, J_{\mathrm{PLC}_{\text {agonist }}}=0.07 \mu \mathrm{M} / \mathrm{s}\right)$. The grids show two possible configurations of the numbered cells. The calcium oscillations of cells colored with the same gray shade are in phase.

disappeared. The branch of periodic orbits emanating from the Hopf bifurcations $\mathrm{HB}_{3}$ and $\mathrm{HB}_{4}$ corresponds to antiphase calcium oscillations and in phase membrane potential oscillations (branch B). With respect to the diagram of identical cells, this branch is still largely stable. However, for agonist concentration between $0.1388 \mu \mathrm{M} / \mathrm{s}$ and $0.1476 \mu \mathrm{M} / \mathrm{s}$, it has become unstable. In this region the behavior of the two cells becomes more complex, but the cells stay out of phase. By comparing the bifurcation diagram of the coupled cells to those of isolated cells, we note that the phenomenon of generation of oscillations is still present between $\mathrm{HB}_{3}$ and $\mathrm{HB}_{1}$, and $\mathrm{HB}_{2}$ and $\mathrm{HB}_{4}$.

Increasing $F_{2}$ extends the domain of complex behaviors and reduces the domain of stability on branch B (see Fig. 8(c) and (d), for $F_{2}=0.25 \mu \mathrm{M} / \mathrm{s}$ ). There is no domain of stability on branch A. The amplitudes of oscillations of the cells differ more and more from each other when $F_{2}$ is increased. At high values of $J_{\mathrm{PLC}_{\text {agonist }}}$, the isolated SMC 2 is in a stable steady state. When the cells are coupled, the antiphase calcium oscillations are drifted by SMC 1. Therefore SMC 1 has large amplitude oscillations, whereas SMC 2 presents small amplitude oscillations. At low values of $J_{\mathrm{PLC}_{\mathrm{agonist}}}$, the situation is reversed: the isolated SMC 1 would be in a stable steady state and presents therefore small amplitude oscillations when coupled, whereas SMC 2 oscillates with a large amplitude. Numerical simulations at $J_{\mathrm{PLC}_{\text {agonist }}}=0.12 \mu \mathrm{M} / \mathrm{s}$ and $J_{\mathrm{PLC}_{\text {agonist }}}=0.15 \mu \mathrm{M} / \mathrm{s}$ for the two cells are given in Fig. 9. Similar behaviors can be observed when $F_{2}$ is decreased below $0.23 \mu \mathrm{M} / \mathrm{s}$.

If we fix $F_{2}=0.234 \mu \mathrm{M} / \mathrm{s}$ and decrease the coupling coefficient $g$, we observe that the domain of stable solutions in branch $\mathrm{B}$ decreases and the range of complex behaviors increases. We obtain similar behaviors for lower values of $g$ at $F_{2}=0.234 \mu \mathrm{M} / \mathrm{s}$, than for $g=100 \mathrm{~s}^{-1}$ and higher values of $F_{2}$. In other words, introducing heterogeneity at lower values of $g$ perturbs the system more than at high values of $g$. This is due to the fact that at 

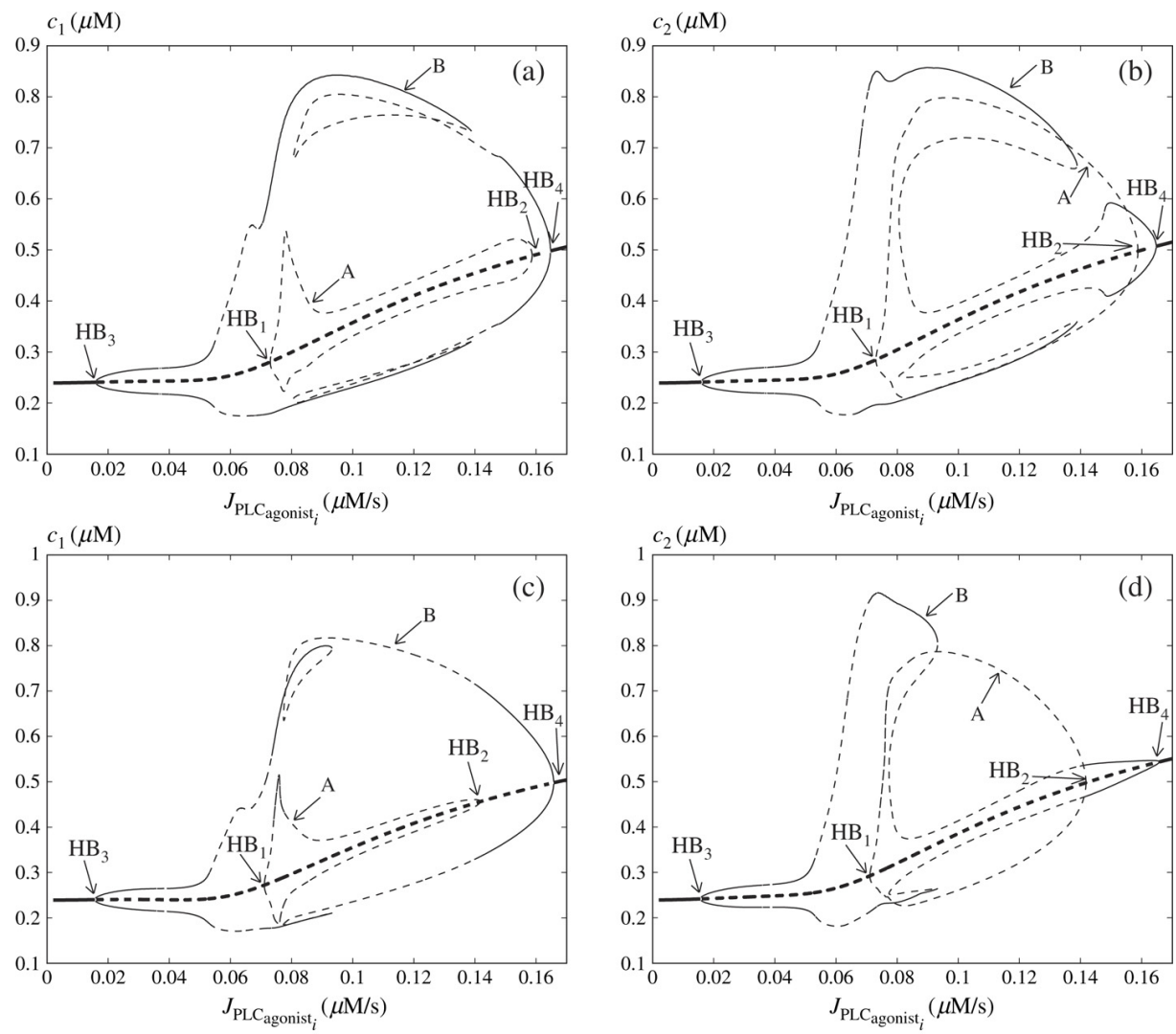

Fig. 8. Bifurcation diagrams for the cytosolic calcium concentrations $c_{i}$ in the case of two non-identical electrically coupled cells $\left(g=100 \mathrm{~s}^{-1}\right)$. (a) and (b): $F_{1}=0.23 \mu \mathrm{M} / \mathrm{s}$ and $F_{2}=0.234 \mu \mathrm{M} / \mathrm{s}$. (c) and (d): $F_{1}=0.23 \mu \mathrm{M} / \mathrm{s}$ and $F_{2}=0.25 \mu \mathrm{M} / \mathrm{s}$ (thick solid line: stable rest state, thick dashed line: unstable rest state, thin solid line: minima and maxima of stable oscillations, thin dashed line: minima and maxima of unstable oscillations). $\mathrm{HB}_{h}(h=1, \ldots, 4)$ denotes a Hopf bifurcation. A and B label branches of periodic orbits.

low values of $g$, the stability of branch B is less strong, i.e. the eigenvalues of the Jacobian matrix are less negative.

By varying other parameters than $F$, we observe that the general behavior remains the same: the in phase calcium oscillation solution rapidly becomes unstable, more complex out of phase calcium oscillations are possible, and the phenomenon of generation of oscillations is still present (data not shown).

We have also considered the effect of heterogeneity in a population of electrically coupled SMCs. Increasing heterogeneity extends the domain of complex behaviors. The probability of group formation is then more and more reduced. For instance, with six nonidentical cells $\left(F_{i}=0.231 \pm 0.002 \mu \mathrm{M} / \mathrm{s}\right)$ stimulated by an agonist concentration of $J_{\mathrm{PLC}_{\text {agonist }}}=0.14 \mu \mathrm{M} / \mathrm{s}$ and arranged as in Fig. 6(b), we do not observe the formation of any groups. Note that in the case of two cells, this value of $J_{\mathrm{PLC}_{\text {agonist }}}$ corresponds to 

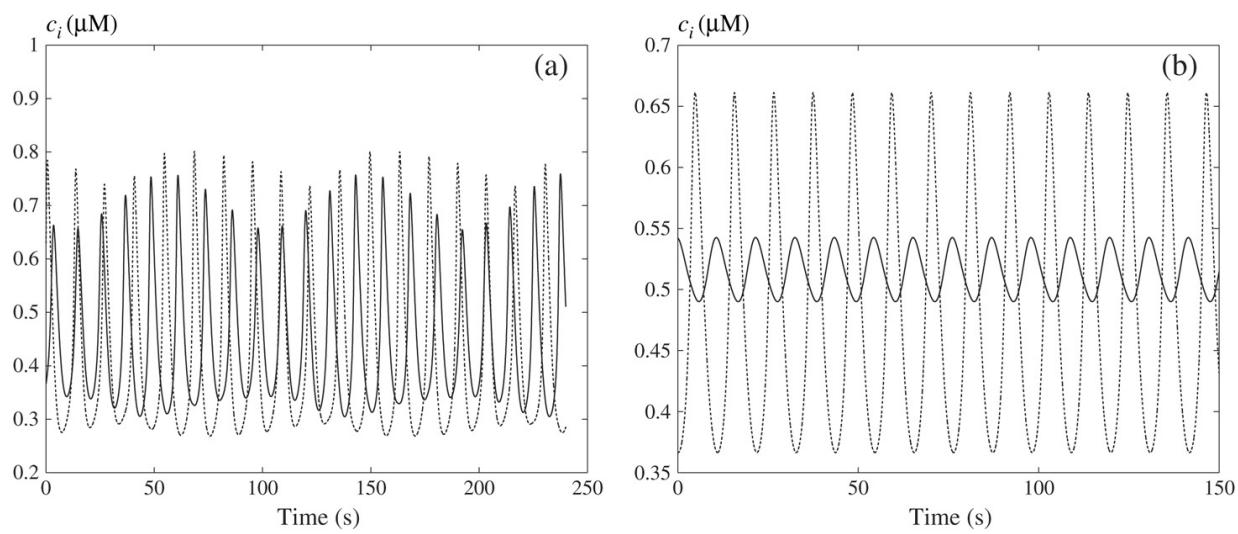

Fig. 9. Numerical simulations of the cytosolic calcium concentrations $c_{i}$ of two non-identical electrically coupled cells $\left(g=100 \mathrm{~s}^{-1}, F_{1}=0.23 \mu \mathrm{M} / \mathrm{s}\right.$ and $F_{2}=0.25 \mu \mathrm{M} / \mathrm{s}$, dotted curve: SMC 1, solid curve: SMC 2$)$. (a) $J_{\mathrm{PLC}_{\text {agonist }}}=0.12 \mu \mathrm{M} / \mathrm{s}$. (b) $J_{\mathrm{PLC}_{\text {agonist }_{i}}}=0.15 \mu \mathrm{M} / \mathrm{s}$.

a region where the solutions are complex (new unstable part of branch B on Fig. 8(a) and (b)). At the lower value $J_{\mathrm{PLC}_{\text {agonist }}}=0.1 \mu \mathrm{M} / \mathrm{s}$ for the same variability $\left(F_{i}=\right.$ $0.231 \pm 0.002 \mu \mathrm{M} / \mathrm{s})$, most of the cells organize themselves in groups, but one or two may oscillate independently. With more heterogeneity $\left(F_{i}=0.235 \pm 0.009 \mu \mathrm{M} / \mathrm{s}\right)$, all the group patterns are lost.

\section{Discussion}

We have shown that two identical electrically coupled SMCs can present a wide variety of behaviors when stimulated by agonists. Their calcium oscillations can be in phase or out of phase. However an unexpected fact is that the out of phase solution is dominant in our study: in Fig. 3, the stability domain of branch B is much more extended than the one of branch A. This is in contrast with calcium coupling for which synchronous solutions are dominant (Koenigsberger et al., 2004). Other detailed bifurcation analysis of two calcium oscillators coupled by calcium diffusion also reveal that in phase solutions are then the most frequent (Höfer, 1999; Bindschadler and Sneyd, 2001). The major difference in our work with respect to the one of Höfer (1999) and Bindschadler and Sneyd (2001) is that we couple calcium oscillators with an equation (membrane potential Eq. (3) completed with term (6)) that is not responsible for oscillations. In our model this brings about the dominance of out of phase solutions and the phenomenon of generation of oscillations. In a population of cells the out of phase effect of electrical coupling gives rise to synchronous oscillations by groups. Cells that are in phase may as well be neighbors as be situated at long distances from each other. Moreover in contrast to the study of Bindschadler and Sneyd (2001), high values for the coupling coefficient do not lead to a bifurcation diagram similar to the one of an uncoupled cell.

The patterns we have obtained in the case of three mutually coupled cells are predicted by a mathematical classification developed by Golubitsky and Stewart (1985). This 
classification relies on geometrical symmetries of coupled oscillator systems, and is independent of the oscillators' internal dynamics. A more complete discussion in the case of square networks of coupled oscillators with nearest neighbor coupling and periodic boundary conditions can be found in Stewart et al. (2003) and Golubitsky et al. (2004). In our simulations, we have obtained extra patterns that are not described in these articles.

An interesting finding of our study is that for all values of electrical coupling oscillations are generated at certain agonist concentrations for which the uncoupled cell is quiescent. As cells are identical, this can only be possible for out of phase calcium oscillations: one cell has to damp and change membrane potential oscillations of the other cell. Indeed, in an uncoupled cell, membrane potential oscillates at the same frequency as the calcium concentration. However when cells are electrically coupled, there are two opposite effects. The first effect tends to let the membrane potential oscillate at the same frequency as the calcium concentration in each cell. The second effect, which is due to electrical coupling, tends to create out of phase calcium oscillations and in phase membrane potential oscillations. It then perturbs membrane potential dynamics in each cell, as membrane potential has to oscillate several times during one calcium oscillation. Therefore the coupling term is non-zero all the time and changes membrane potential dynamics with respect to an uncoupled cell. In contrast, if calcium oscillations are in phase, the coupling term is zero and it cannot have any effect on calcium dynamics. The mechanism of generation of oscillations exposed in our work is general and can be applied to other theoretical models. Necessary conditions for this generation of oscillations are that the model incorporates equations responsible for oscillatory behavior and that the intercellular coupling takes place in another equation following passively the previous ones. Moreover the coupling must change the dynamics of the variable of the equation following passively the oscillator in such a way that a Hopf bifurcation can be reached to generate oscillations. By setting the variables $w_{i}$ and $I_{i}$ to a fixed value, we have verified that in our model the three internal variables $c_{i}, s_{i}$ and $v_{i}$ are necessary and sufficient to generate oscillations. An explicit example in which oscillations arise through coupling is given by Smale (1974). This example involves at least four internal variables.

The fact that in our study electrical coupling does not synchronize the calcium oscillations is dependent on our particular choice of parameters. In our model, the intracellular oscillator is responsible for the oscillations as suggested by the experimental observations of Hamada et al. (1997) and Haddock et al. (2002). This leads to asynchronous calcium oscillations as a consequence of electrical coupling, which is not expected intuitively. If the parameters are chosen in such a way that the membrane potential drives the oscillations, the effects of electrical coupling could be different. However our aim here was to present a possible way to generate calcium oscillations by electrical coupling, which is possible when the intracellular oscillator is responsible for oscillations.

The introduction of heterogeneity among cells destroys the stability of the solution corresponding to synchronous calcium oscillations. The antiphase solution remains largely stable provided the cells are not too different. The phenomenon of generation of oscillations is still present, but the group formation pattern in a population is sensitive to the degree of variability.

Experimentally, as Savineau and Marthan (2000) reviewed, the behavior of isolated SMCs in response to agonist stimulation is very variable: some types of SMCs are 
oscillating, whereas others present only a transient calcium increase. The same type of SMCs that present only transient increases when freshly dispersed may oscillate when they are coupled (Fanchaouy et al., 2005). Furthermore, spontaneous calcium oscillations were observed in cultured aortic SMCs in the confluent condition, but not in single cells or in cells in the subconfluent condition (Simpson and Ashley, 1989; Missiaen et al., 1994). Our model may provide an explanation for such phenomena. For a population of cells, we observe that the out of phasing effect of electrical coupling gives rise to synchronous oscillations by groups. Cells that are in phase may as well be neighbors as be situated at long distances from each other. During the oscillations, the mean calcium level is elevated, and asynchronous oscillations leading to a tonic contraction have been reported (Iino et al., 1994; Ruehlmann et al., 2000; Zang et al., 2001). It remains to be verified if these oscillations could correspond to a pattern of synchronous and asynchronous oscillations modeled in the present study. Heterogeneity among cells and experimental noise (calcium fluctuations due to stochastic opening and closing of channels) can perturb this pattern, and the time necessary to converge to a stable configuration may be too long. Our simulations also show that complex behaviors, such as multiply periodic orbits, can occur for a non negligible range of agonist concentrations, and we could expect to observe these behaviors experimentally.

\section{Acknowledgement}

This research was supported by the Swiss National Science Foundation Grant FN 3152-067939.

\section{Appendix A. Details of the mathematical model}

The quantity $J_{\mathrm{IP} 3_{i}}$ in Eq. (1) represents the calcium release from the stores possessing $\mathrm{IP}_{3}$-receptors. It is directly related to the $\mathrm{IP}_{3}$ concentration:

$$
J_{\mathrm{IP} 3_{i}}=F \frac{I_{i}^{2}}{K_{\mathrm{r}}^{2}+I_{i}^{2}} .
$$

The term

$$
J_{\mathrm{VOCC}_{i}}=G_{\mathrm{Ca}} \frac{v_{i}-v_{\mathrm{Ca}_{1}}}{1+\mathrm{e}^{-\left[\left(v_{i}-v_{\mathrm{Ca}_{2}}\right) / R_{\mathrm{Ca}}\right]}}
$$

models the calcium influx through voltage operated calcium channels (VOCCs),

$$
J_{\mathrm{Na} / \mathrm{Ca}_{i}}=G_{\mathrm{Na} / \mathrm{Ca}} \frac{c_{i}}{c_{i}+c_{\mathrm{Na} / \mathrm{Ca}}}\left(v_{i}-v_{\mathrm{Na} / \mathrm{Ca}}\right)
$$

the $\mathrm{Na}^{+} / \mathrm{Ca}^{2+}$ exchange,

$$
J_{\text {SRuptake }_{i}}=B \frac{c_{i}^{2}}{c_{i}^{2}+c_{\mathrm{b}}^{2}}
$$


the SR uptake,

$$
J_{\mathrm{CICR}_{i}}=C \frac{s_{i}^{2}}{s_{\mathrm{c}}^{2}+s_{i}^{2}} \frac{c_{i}^{4}}{c_{\mathrm{c}}^{4}+c_{i}^{4}}
$$

the calcium induced calcium release (CICR),

$$
J_{\text {extrusion }_{i}}=D c_{i}\left(1+\frac{v_{i}-v_{\mathrm{d}}}{R_{\mathrm{d}}}\right)
$$

the calcium extrusion from the SMC by $\mathrm{Ca}^{2+}-\mathrm{ATPase}$ pumps,

$$
J_{\text {leak }_{i}}=L s_{i}
$$

the leak from the SR,

$$
J_{\mathrm{Na} / \mathrm{K}_{i}}=F_{\mathrm{Na} / \mathrm{K}}
$$

the $\mathrm{Na}^{+}-\mathrm{K}^{+}-$ATPase,

$$
J_{\mathrm{Cl}_{i}}=G_{\mathrm{Cl}}\left(v_{i}-v_{\mathrm{Cl}}\right)
$$

the chloride channels,

$$
J_{\mathrm{K}_{i}}=G_{\mathrm{K}} w_{i}\left(v_{i}-v_{\mathrm{K}}\right)
$$

the $\mathrm{K}^{+}$efflux and

$$
K_{\text {activation }_{i}}=\frac{\left(c_{i}+c_{\mathrm{W}}\right)^{2}}{\left(c_{i}+c_{\mathrm{W}}\right)^{2}+\beta \mathrm{e}^{-\left[\left(v_{i}-v_{\mathrm{Ca}_{3}}\right) / R_{\mathrm{K}}\right]}}
$$

the calcium and voltage activation of $\mathrm{K}^{+}$channels. The constant $J_{\mathrm{PLC}_{\text {agonist }}}$ is the rate of the PLC activated by receptor-ligand agonists, while the term

$$
J_{\mathrm{PLC} \delta_{i}}=E \frac{c_{i}^{2}}{K_{\mathrm{Ca}}^{2}+c_{i}^{2}}
$$

models the PLC- $\delta$. Finally, $J_{\text {degrad }_{i}}=k I_{i}$ expresses $\mathrm{IP}_{3}$ degradation.

The meaning of the parameters is given in Table A.1. The numerical values of the parameters (except $v_{\mathrm{Na} / \mathrm{Ca}}$ ) are taken from Koenigsberger et al. (2004). 
Table A.1

Parameter values for the single cell model (Koenigsberger et al., 2004)

\begin{tabular}{|c|c|c|}
\hline Parameter & Description & Units and value \\
\hline$G_{\mathrm{Ca}}$ & Whole cell conductance for VOCCs & $0.00129 \mu \mathrm{M} \mathrm{mV}^{-1} \mathrm{~s}^{-1}$ \\
\hline$v_{\mathrm{Ca}_{1}}$ & Reversal potential for VOCCs & $100.0 \mathrm{mV}$ \\
\hline$v_{\mathrm{Ca}_{2}}$ & Half-point of the VOCC activation sigmoidal & $-24.0 \mathrm{mV}$ \\
\hline$R_{\mathrm{Ca}}$ & $\begin{array}{l}\text { Maximum slope of the VOCC activation } \\
\text { sigmoidal }\end{array}$ & $8.5 \mathrm{mV}$ \\
\hline$G_{\mathrm{Na} / \mathrm{Ca}}$ & $\begin{array}{l}\text { Whole cell conductance for } \mathrm{Na}^{+} / \mathrm{Ca}^{2+} \text { ex- } \\
\text { change }\end{array}$ & $0.00316 \mu \mathrm{M} \mathrm{mV}^{-1} \mathrm{~s}^{-1}$ \\
\hline$c_{\mathrm{Na} / \mathrm{Ca}}$ & $\begin{array}{l}\text { Half-point for activation of } \mathrm{Na}^{+} / \mathrm{Ca}^{2+} \text { ex- } \\
\text { change by } \mathrm{Ca}^{2+}\end{array}$ & $0.5 \mu \mathrm{M}$ \\
\hline$v_{\mathrm{Na} / \mathrm{Ca}}$ & Reversal potential for the $\mathrm{Na}^{+} / \mathrm{Ca}^{2+}$ exchanger & $-30.0 \mathrm{mV}$ \\
\hline$B$ & SR uptake rate constant & $2.025 \mu \mathrm{M} / \mathrm{s}$ \\
\hline$c_{\mathrm{b}}$ & $\begin{array}{l}\text { Half-point of the SR ATPase activation sig- } \\
\text { moidal }\end{array}$ & $1.0 \mu \mathrm{M}$ \\
\hline$C$ & CICR rate constant & $55 \mu \mathrm{M} / \mathrm{s}$ \\
\hline$s_{\mathrm{c}}$ & Half-point of the CICR $\mathrm{Ca}^{2+}$ efflux sigmoidal & $2.0 \mu \mathrm{M}$ \\
\hline$c_{\mathrm{c}}$ & Half-point of the CICR activation sigmoidal & $0.9 \mu \mathrm{M}$ \\
\hline$D$ & $\begin{array}{l}\text { Rate constant for } \mathrm{Ca}^{2+} \text { extrusion by the ATPase } \\
\text { pump }\end{array}$ & $0.24 \mathrm{~s}^{-1}$ \\
\hline$v_{\mathrm{d}}$ & $\begin{array}{l}\text { Intercept of voltage dependence of extrusion } \\
\text { ATPase }\end{array}$ & $-100.0 \mathrm{mV}$ \\
\hline$R_{\mathrm{d}}$ & $\begin{array}{l}\text { Slope of voltage dependence of extrusion } \\
\text { ATPase }\end{array}$ & $250.0 \mathrm{mV}$ \\
\hline$L$ & Leak from SR rate constant & $0.025 \mathrm{~s}^{-1}$ \\
\hline$\gamma$ & $\begin{array}{l}\text { Scaling factor relating net movement of ion } \\
\text { fluxes to the membrane potential } \\
\text { (inversely related to cell capacitance) }\end{array}$ & $1970 \mathrm{mV} / \mu \mathrm{M}$ \\
\hline$F_{\mathrm{Na} / \mathrm{K}}$ & Net whole cell flux via the $\mathrm{Na}^{+}-\mathrm{K}^{+}-$ATPase & $0.0432 \mu \mathrm{M} / \mathrm{s}$ \\
\hline$G_{\mathrm{Cl}}$ & Whole cell conductance for $\mathrm{Cl}^{-}$current & $0.00134 \mu \mathrm{M} \mathrm{mV}^{-1} \mathrm{~s}^{-1}$ \\
\hline$v_{\mathrm{Cl}}$ & Reversal potential for $\mathrm{Cl}^{-}$channels & $-25.0 \mathrm{mV}$ \\
\hline$G_{\mathrm{K}}$ & Whole cell conductance for $\mathrm{K}^{+}$efflux & $0.00446 \mu \mathrm{M} \mathrm{mV}^{-1} \mathrm{~s}^{-1}$ \\
\hline$v_{\mathrm{K}}$ & Reversal potential for $\mathrm{K}^{+}$ & $-94.0 \mathrm{mV}$ \\
\hline$\lambda$ & Rate constant for net $\mathrm{K}_{\mathrm{Ca}}$ channel opening & 45.0 \\
\hline$c_{\mathrm{W}}$ & $\begin{array}{l}\text { Translation factor for } \mathrm{Ca}^{2+} \text { dependence of } \mathrm{K}_{\mathrm{Ca}} \\
\text { channel activation sigmoidal }\end{array}$ & $0 \mu \mathrm{M}$ \\
\hline$\beta$ & $\begin{array}{l}\text { Translation factor for membrane potential } \\
\text { dependence of } \mathrm{K}_{\mathrm{Ca}} \\
\text { channel activation sigmoidal }\end{array}$ & $0.13 \mu \mathrm{M}^{2}$ \\
\hline$v_{\mathrm{Ca}_{3}}$ & $\begin{array}{l}\text { Half-point for the } \mathrm{K}_{\mathrm{Ca}} \text { channel activation } \\
\text { sigmoidal }\end{array}$ & $-27.0 \mathrm{mV}$ \\
\hline$R_{\mathrm{K}}$ & Maximum slope of the $\mathrm{K}_{\mathrm{Ca}}$ activation sigmoidal & $12.0 \mathrm{mV}$ \\
\hline$E$ & Maximal rate of PLC- $\delta$ & $0 \mu \mathrm{M} / \mathrm{s}$ \\
\hline$K_{\mathrm{Ca}}$ & $\begin{array}{l}\text { Half-saturation constant for calcium activation } \\
\text { of PLC- } \delta\end{array}$ & $0.3 \mu \mathrm{M}$ \\
\hline$k$ & Rate constant of $\mathrm{IP}_{3}$ degradation & $0.1 \mathrm{~s}^{-1}$ \\
\hline$K_{\mathrm{r}}$ & $\begin{array}{l}\text { Half saturation constant for agonist-dependent } \\
\text { calcium entry }\end{array}$ & $1 \mu \mathrm{M}$ \\
\hline$F$ & $\begin{array}{l}\text { Maximal rate of activation dependent calcium } \\
\text { influx }\end{array}$ & $0.23 \mu \mathrm{M} / \mathrm{s}$ \\
\hline
\end{tabular}




\section{References}

Bindschadler, M., Sneyd, J., 2001. A bifurcation analysis of two coupled calcium oscillators. Chaos 11, $237-246$. Christ, G.J., Moreno, A.P., Melman, A., Spray, D.C., 1992. Gap junction-mediated intercellular diffusion of $\mathrm{Ca}^{2+}$ in cultured human corporal smooth muscle cells. Am. J. Physiol. 263, C373-C383.

Cuthbertson, K.S., Cobbold, P.H., 1985. Phorbol ester and sperm activate mouse oocytes by inducing sustained oscillations in cell $\mathrm{Ca}^{2+}$. Nature $316,541-542$.

Fanchaouy, M., Serir, K., Meister, J.J., Bény, J.L., Bychkov, R., 2005. Intercellular communication: role of gap junctions in establishing the pattern of atp elicited $\mathrm{Ca}^{2+}$ oscillations and $\mathrm{Ca}^{2+}$-dependent currents in freshly isolated aortic smooth muscle cells. Cell Calcium 37, 25-34.

Golubitsky, M., Nicol, M., Stewart, I., 2004. Some curious phenomena in coupled cell networks. J. Nonlinear Sci. 14, 207-236.

Golubitsky, M., Stewart, I., 1985. Hopf-bifurcation in the presence of symmetry. Arch. Ration. Mech. Anal. 87, 107-165.

Haberichter, T., Roux, E., Marhl, M., Mazat, J.P., 2002. The influence of different insp(3) receptor isoforms on $\mathrm{Ca}^{2+}$ signaling in tracheal smooth muscle cells. Bioelectrochemistry 57, 129-138.

Haddock, R.E., Hirst, G.D., Hill, C.E., 2002. Voltage independence of vasomotion in isolated irideal arterioles of the rat. J. Physiol. 540, 219-229.

Hamada, H., Damron, D.S., Hong, S.J., VanWagoner, D.R., Murray, P.A., 1997. Phenylephrine-induced Ca ${ }^{2+}$ oscillations in canine pulmonary artery smooth muscle cells. Circ. Res. 81, 812-823.

Höfer, T., 1999. Model of intercellular calcium oscillations in hepatocytes: synchronization of heterogeneous cells. Biophys. J. 77, 1244-1256.

Höfer, T., Politi, A., Heinrich, R., 2001. Intercellular $\mathrm{Ca}^{2+}$ wave propagation through gap-junctional $\mathrm{Ca}^{2+}$ diffusion: a theoretical study. Biophys. J. 80, 75-87.

Höfer, T., Venance, L., Giaume, C., 2002. Control and plasticity of intercellular calcium waves in astrocytes: a modeling approach. J. Neurosci. 22, 4850-4859.

Iino, M., Kasai, H., Yamazawa, T., 1994. Visualization of neural control of intracellular $\mathrm{Ca}^{2+}$ concentration in single vascular smooth muscle cells in situ. EMBO. J. 13, 5026-5031.

Koenigsberger, M., Sauser, R., Lamboley, M., Bény, J.L., Meister, J.J., 2004. $\mathrm{Ca}^{2+}$ dynamics in a population of smooth muscle cells: Modeling the recruitment and synchronization. Biophys. J. 87, 92-104.

Lamboley, M., Schuster, A., Bény, J.L., Meister, J.J., 2003. Recruitment of smooth muscle cells and arterial vasomotion. Am. J. Physiol. Heart Circ. Physiol. 285, H562-H569.

Lee, C.H., Poburko, D., Sahota, P., Sandhu, J., Ruehlmann, D.O., van Breemen, C., 2001. The mechanism of phenylephrine-mediated $\left[\mathrm{Ca}^{2+}\right]_{i}$ oscillations underlying tonic contraction in the rabbit inferior vena cava. J. Physiol. 534, 641-650.

Mauban, J.R., Lamont, C., Balke, C.W., Wier, W.G., 2001. Adrenergic stimulation of rat resistance arteries affects $\mathrm{Ca}^{2+}$ sparks, $\mathrm{Ca}^{2+}$ waves, and $\mathrm{Ca}^{2+}$ oscillations. Am. J. Physiol. Heart Circ. Physiol. 280, H2399-H2405.

Minneman, K.P., 1988. Alpha 1-adrenergic receptor subtypes, inositol phosphates, and sources of cell $\mathrm{Ca}^{2+}$. Pharmacol. Rev. 40, 87-119.

Missiaen, L., Oike, M., Bootman, M.D., DeSmedt, H., Parys, J.B., Casteels, R., 1994. Vasopressin responses in electrically coupled a7r5 cells. Pflugers Arch. 428, 283-287.

Parthimos, D., Edwards, D.H., Griffith, T.M., 1999. Minimal model of arterial chaos generated by coupled intracellular and membrane $\mathrm{Ca}^{2+}$ oscillators. Am. J. Physiol. 277, H1119-H1144.

Peng, H., Matchkov, V., Ivarsen, A., Aalkjaer, C., Nilsson, H., 2001. Hypothesis for the initiation of vasomotion. Circ. Res. 88, 810-815.

Ruehlmann, D.O., Lee, C.H., Poburko, D., van Breemen, C., 2000. Asynchronous $\mathrm{Ca}^{2+}$ waves in intact venous smooth muscle. Circ. Res. 86, E72-E79.

Savineau, J.P., Marthan, R., 2000. Cytosolic calcium oscillations in smooth muscle cells. News Physiol. Sci. 15, 50-55.

Sell, M., Boldt, W., Markwardt, F., 2002. Desynchronising effect of the endothelium on intracellular $\mathrm{Ca}^{2+}$ concentration dynamics in vascular smooth muscle cells of rat mesenteric arteries. Cell Calcium 32, $105-120$.

Simpson, A.W., Ashley, C.C., 1989. Spontaneous oscillations and agonist-evoked changes in $\mathrm{Ca}^{2+}$ in cultured smooth muscle cells. J. Cardiovasc. Pharmacol. 14 (Suppl. 6), S59-S62. 
Smale, S., 1974. A mathematical model of two cells via turing's equation. In: Lectures on Mathematics in the Life Sciences. The American Mathematical Society, Providence, RI, pp. 17-26.

Sneyd, J., Wetton, B.T., Charles, A.C., Sanderson, M.J., 1995. Intercellular calcium waves mediated by diffusion of inositol trisphosphate: a two-dimensional model. Am. J. Physiol. 268, C1537-C1545.

Stewart, I., Golubitsky, M., Pivato, M., 2003. Symmetry groupoids and patterns of synchrony in coupled cell networks. Siam J. Appl. Dyn. Syst. 2, 609-646.

Tasker, P.N., Michelangeli, F., Nixon, G.F., 1999. Expression and distribution of the type 1 and type 3 inositol 1,4, 5-trisphosphate receptor in developing vascular smooth muscle. Circ. Res. 84, 536-542.

Tordjmann, T., Berthon, B., Claret, M., Combettes, L., 1997. Coordinated intercellular calcium waves induced by noradrenaline in rat hepatocytes: dual control by gap junction permeability and agonist. EMBO. J. 16, 5398-5407.

Verselis, V., White, R.L., Spray, D.C., Bennett, M.V., 1986. Gap junctional conductance and permeability are linearly related. Science 234, 461-464.

Woods, N.M., Cuthbertson, K.S., Cobbold, P.H., 1986. Repetitive transient rises in cytoplasmic free calcium in hormone-stimulated hepatocytes. Nature 319, 600-602.

Zang, W.J., Balke, C.W., Wier, W.G., 2001. Graded alpha1-adrenoceptor activation of arteries involves recruitment of smooth muscle cells to produce 'all or none' $\mathrm{Ca}^{2+}$ signals. Cell Calcium 29, 327-334. 